\title{
El traductor visible de literatura poscolonial ante la tentación del exotismo
}

\author{
Goretti López Heredia \\ Universitat Oberta de Catalunya
}

\begin{abstract}
Building upon The Translator's Invisibility by L. Venuti and related work by Susan Bassnett, Ovidi Carbonell, Anuradha Dingwaney, Samia Mehrez and Mahasweta Sengupta, among others, this paper argues for the visibility of the postcolonial literature translator and draws a carefull line between proper visibility - as we define it - and a counterproductive exotism that may arise as the side-product of a poorly understood visibility. Our discussion focuses on the particular case of postcolonial lusophone African literature. In particular, we analyze the translation strategy adopted by the author of this paper for the translation from portuguese to catalan of A Varanda do Frangipani, a novel by Mia Couto from Mozambique.
\end{abstract}

\section{Traducción-creación y traducción de culturas}

En la introducción al libro Between languages and cultures: translation and cross-cultural texts, Anuradha Dingwaney presenta así el vasto campo que se abrió ante la teoría de la traducción al incluir en su ámbito de investigación las literaturas poscoloniales:

Translation is one of the primary means by which texts written in one or another indigenous language of the various countries arbitrarily grouped under the "Third", or non-Western, World are made available in western, metropolitan languages. However, translation is not restricted to such linguistic transfers alone: translation is also the vehicle through which "Third World" cultures (are made to) travel - transported or "borne across" to and recuperated by audiences in the West. Thus, even texts written in English or in one of the metropolitan languages, but originating in or about non-Western cultures, can be considered under the rubric of translation. (1995: 4)

Esta declaración de principios es una muestra de la riqueza de significados y de procesos que abarca la palabra traducción en el contexto de la literatura poscolonial escrita en lenguas coloniales. En lo que sigue, a partir de ejemplos extraídos de la novela del escritor mozambiqueño Mia Couto A Varanda do Frangipani y de su traducción al catalán, se explicarán dos procesos traductológicos, que conciernen respectivamente al escritor poscolonial y al traductor de literatura poscolonial.

A modo de breve presentación de la novela, sobre el telón de fondo del Mozambique posterior a la independencia, Mia Couto construye una trama policiaca. El director de una residencia de ancianos situada en una fortaleza al lado del mar en un lugar apartado de Mozambique es asesinado. El 
inspector de policía Izidine Naíta acude a dicha residencia para analizar los hechos e interrogar uno por uno a todos los ancianos que residen allí. Sus indagaciones durarán una semana, el tiempo en el que transcurre el relato.

El primer proceso traductológico, la traducción-creación, tiene que ver con la manera particular con que ciertos escritores poscoloniales moldean las lenguas coloniales. ${ }^{1}$ Los escritores que adoptan esta estrategia transmiten en sus obras la hibridación inherente a las sociedades poscoloniales mediante procedimientos estilísticos que en muchos casos les llevan a 'mestizar' lenguas coloniales y lenguas nacionales. Moradewun Adejunmobi llega a caracterizar este proceso, que denomina compositional translation, como una manifestación de rebeldía por parte de ciertos escritores poscoloniales contra la dominación occidental a la que las sociedades colonizadas se han visto sometidas, cuyas consecuencias siguen sufriendo en la actualidad:

I will identify as compositional translations texts which are published in European languages and which contain occasional or sustained modification of the conventions of the European language in use, where 'versions' or 'originals' in indigenous African languages are non-existent. [...] It should be noted, furthermore, that the modification of European languages in these texts generally results from a deliberate intent to indigenize the European language. (1998: 165)

El escritor poscolonial así descrito recurre a sus orígenes adoptando una herramienta de expresión, las lenguas coloniales, y un soporte, la escritura, que revelan su pertenencia a un mundo marcado por el fenómeno colonial que ha sabido desde el interior forjar sus propias armas de resistencia y de superación. Por ello, uno de los recursos transgresores de los escritores poscoloniales en lenguas coloniales consiste en poner por escrito la lengua corriente, oral, mestiza, utilizada en las antiguas colonias durante y después de la descolonización. Institucionalizar ese uso de la lengua es un acto subversivo. La escritura es una manera de conceder a las lenguas coloniales el estatus de lenguas válidas per se, al mismo nivel que las variantes occidentales.

El escritor poscolonial, como el traductor, debe asumir su función de puente entre culturas. Este esfuerzo de re-invención del lenguaje es un rasgo propio de la literatura poscolonial escrita en lenguas coloniales. De ahí que la teoría poscolonial y la investigación más reciente en teoría de la traducción reconozcan a los escritores que han adoptado dichas lenguas como herramientas de creación en tanto que creadores y traductores al mismo tiempo. A este propósito nos parece muy reveladora la comparación entre la traducción literaria y la creación poscolonial llevada a cabo por Maria Tymoczko en su artículo "Post-colonial writing and literary translation":

The culture or tradition of a post-colonial writer acts as a metatext which is rewritten - explicitly and implicitly, as both background and foreground - in the act of literary creation. The task of the interlingual translator has much in common with the task of the post-colonial writer, where one has a text, however, the other has the metatext of culture itself. (Tymoczko 1999: 21) 
Lo interesante del paralelismo que propone la susodicha investigadora es que resalta la importancia del factor cultural en ambos casos. Como ocurre en la transferencia de un texto entre dos lenguas, el metatexto cultural sobre el que trabaja el escritor poscolonial y que desea transferir por escrito, debe pasar por un tamiz lingüístico, el de la lengua colonial, y las limitaciones que eso comporta, la simplificación que de ambos procesos resulta - si coincidimos con Maria Tymoczko en reconocer la imposibilidad de restituir íntegramente en una lengua el texto o metatexto cultural expresado en otra lengua -, constituye uno de los puntos de convergencia entre ambas operaciones.

En el segundo proceso traductológico, que se refiere a la traducción en su sentido más corriente, como operación de transferencia de un texto de una lengua de partida a otra de llegada, el lector intermediario (es decir, el traductor) tiene que considerar el contexto cultural en el que se ha producido la obra original y tratar de identificar la impronta que ha dejado la historia de la colonización en las lenguas coloniales sin juicios de valor. De lo contrario, como veremos en lo que sigue, lo que prevalecerá en su texto de llegada es una lectura imperialista de esos textos: los leerá como discursos exóticos e intentará transmitir ese exotismo a los lectores europeos. La traducción de literatura poscolonial se asemeja más a un trasvase de culturas que a una operación puramente lingüística. Por eso adoptaremos desde ahora la denominación de traducción de culturas, en clara alusión al término de cultural translation acuñado por el teórico poscolonial Homi Bhabha ${ }^{2}$ para referirnos a la traducción literaria de un texto poscolonial de características similares a las de la novela de Mia Couto.

Si interpretamos desde una perspectiva metafórica los personajes principales que intervienen en A Varanda do Frangipani, una figura femenina aparece como la encarnación del traductor de culturas. A lo largo de la encuesta policial, Marta, la enfermera de la residencia donde transcurre la trama, es capaz de viajar entre las dos concepciones del lenguaje manejadas, por un lado, por Izidine Naíta, que pertenece a la generación de jóvenes mozambiqueños formados en Portugal y, por otro lado, por los ancianos mozambiqueños, completamente silenciados en la sociedad moderna dominante después de la independencia de Mozambique. Marta forma parte del universo poscolonial. Es capaz de interpretar el desencuentro entre palabras e ideas que en ocasiones afecta a los hablantes de una lengua impuesta y de transmitir el universo tradicional a un negro-blanco - así se denominaba en las antiguas colonias africanas lusófonas a los negros que habían adoptado el modo de vida occidental - procedente de un contexto urbano, como el inspector. En su calidad de personaje híbrido, sabe descodificar los trazos minorizantes del portugués hablado por sus pacientes y de señalar con el dedo a los mozambiqueños que no han sabido desvincularse del influjo de la ideología colonial y que han creado una profunda herida interna en una sociedad formalmente liberada del yugo colonial mediante la adopción del lenguaje de la exclusión. 
En el siguiente apartado queremos resaltar particularmente la manera como el traductor de culturas se afronta al texto híbrido creado por el traductor-creador, en su dimensión ideológica (como transmisor de cierta imagen del Otro) y en su dimensión cultural y lingüística. De este modo, basándonos en la teoría de Lawrence Venuti sobre la invisibilidad del traductor, haremos hincapié en el riesgo que comporta una postura gratuitamente visible del traductor de literatura poscolonial. Con ello, queremos insistir en el peligro que supone una lectura en clave exótica de la imagen del Otro en el original poscolonial, puesto que conlleva forzosamente la adopción de estrategias lingüísticas en nuestra opinión erróneas.

\section{La práctica de la visibilidad del traductor de culturas}

Como hemos podido observar, todas las estrategias de creación literaria que hemos descrito referidas a la traducción-creación y que caracterizan una parte importante de la producción poscolonial suponen para el traductor interlingüístico un esfuerzo suplementario y permiten considerar su labor como una operación de re-traducción dentro de la transferencia escrita entre dos o más lenguas. El profesor Michel Laban, traductor al francés de las obras más reconocidas de literatura poscolonial africana lusófona, en el décimo primer congreso de traducción literaria celebrado en Arles en 1994, comentaba a este propósito:

\footnotetext{
Quand je traduis un texte africain, je me trouve face à l'immense obstacle qui est celui de traduire plusieurs langues en même temps. Traduire Luandino Vieira, d'Angola, c'est traduire du portugais standard, et là ça va; c'est aussi traduire du portugais de Luanda, la capitale de l'Angola, et là c'est déjà plus difficile, il faut être au courant de toutes les subtilités, il y a un décalage par rapport à la norme de Lisbonne. C'est aussi traduire souvent des termes du kimbundu, une langue africaine de la région de Luanda. C'est ensuite traduire des créations propres à l'auteur. (1995: 46-47)
}

Estas declaraciones de Michel Laban a propósito del multilingüísmo inherente a la obra del angoleño Luandino Vieira, podrían ser igualmente aplicadas a otros muchos escritores africanos del área lusófona que escriben en portugués. Efectivamente, los angoleños Pepetela y Luandino Vieira, y los mozambiqueños José Craveirinha, Suleiman Cassamo, Pauline Chiziane así como el mismo Mia Couto, entre otros, plasman en la escritura literaria el entorno multicultural del que proceden. La traducción interlinguiística en el contexto que venimos definiendo se suma a la preocupación que subyace a toda la teoría poscolonial: ¿cómo integrar una producción literaria muy amplia y variada originada en la periferia del sistema literario occidental (hasta mediados de este siglo reconocidamente encerrado en sí mismo) en Occidente? Dicho de otra manera, ¿cómo pueden superarse a través de la traducción los prejuicios que han marcado las relaciones no sólo literarias, sino también políticas, económicas entre Occidente y sus ex-colonias para poder 
hablar de un solo sistema literario, sin distinciones discriminatorias? Y ¿cómo puede la literatura poscolonial traducida librarse de la etiqueta de 'literatura exótica' para ser considerada simplemente 'literatura'? Antes de responder a estos interrogantes, nos permitimos un rodeo para recordar los principios que, según Venuti, deben permitir al traductor interlingüístico tener un papel más visible.

En su libro The Translator's Invisibility, Venuti denuncia la homogeneización que impera en las traducciones al inglés en los Estados Unidos y Gran Bretaña de textos literarios escritos en otras lenguas. Durante los últimos tres siglos el criterio de aceptabilidad de una traducción (que puede aplicarse también al mercado europeo) ha sido la fluidez, la eliminación de cualquier asperidad lingüística o cultural que pudiera hacer pensar al lector que está leyendo un texto traducido. La máxima que domina esta concepción traductológica es que toda traducción debe leerse como un original. Las consecuencias de esta estrategia son claras: lo importante es obtener un texto de destino llano para evitar cualquier efecto de extrañamiento o cualquier marca de diferencia. Se trata de moldear, en definitiva, toda escritura extranjera según las normas literarias y sociales preponderantes en la cultura de destino.

En el caso de la literatura poscolonial, cuyo discurso se basa precisamente en la acentuación de la diferencia, este allanamiento ha sido denunciado por varios teóricos. Venuti explica así los requisitos para que una traducción sea aceptable según el modelo anglo-norteamericano - es decir, invisible, transparente y domesticada:

A fluent translation is written in English that is current ('modern') instead of archaic, that is widely used instead of specialized ('jargonisation'), and that is standard instead of colloquial ('slangly') [...] a fluent translation that is immediately recognizable and intelligible, 'familiarised', 'domesticated', not 'disconcertingly'. (Venuti 1995: 4-5)

El texto poscolonial es ininteligible (desde el punto de vista del lector occidental poco informado), inesperado (en el sentido de que con frecuencia no responde a nuestras expectativas de lo que consideramos una obra literaria) y desconcertante por definición. ¿Cómo puede entonces conjugarse la práctica de la invisibilidad de la traducción con la literatura poscolonial? Aplicar los principios según los cuales una traducción, cualquiera que sea su lenguacultura de origen, debe estar escrita en un lenguaje moderno, corriente y estándar equivale a no respetar las particularidades de cada tradición literaria y, en el caso de la literatura poscolonial, a anular su razón de ser, que es precisamente la acentuación de la diferencia. Estas normas que rigen el mercado de la traducción al inglés (y que predominan en otros países occidentales) corresponden al modelo de lector occidental monolingüe, que lee o interpreta el mundo desde un punto de vista eurocéntrico, nada receptivo a lo extranjero y que exige un producto literario totalmente pulido y depurado de elementos desconocidos para consumirlo sin dificultad. 
Uno de los principios - derivados de la práctica de la invisibilidad que el ejercicio de la traducción de literatura poscolonial pone en tela de juicio es la equivalencia unidireccional entre significado y significante. Las literaturas que han surgido del contacto entre colonizadores y colonizados y del uso de las lenguas coloniales en contextos muy distintos demuestran precisamente que el significado de las palabras se modifica, se amplía o se reduce en función de cada contexto socio-cultural. Asimismo, cada traducción constituye un recorrido particular por la multiplicidad de posibilidades semánticas que engloba un original, y que puede variar según el momento histórico, o la coyuntura social de la cultura de origen y la de destino. El texto poscolonial, a la vista de la teoría de la traducción, es la demostración paradigmática de que la creación de significados depende totalmente del contexto socio-cultural donde se lleve a cabo. Así, la validez de una traducción no puede basarse en la mera equivalencia semántica, puesto que, por un lado, el texto original es susceptible de muchas interpretaciones distintas, y por otro lado, las decisiones interpretativas del traductor responden a una coyuntura cultural determinada en el contexto de destino, lo cual significa que superan el texto original en sí. Esto quiere decir, en definitiva, que los cánones de ajuste o de adecuación son culturalmente específicos e históricamente variables. Cuestión crucial para los traductores, puesto que inutiliza la búsqueda de fidelidad al original y exige la adopción de otro criterio para valorar una traducción.

Venuti describe el proceso de domesticación de un texto extranjero como un proceso de manipulación excesiva por oposición a otra estrategia traductológica: la extranjerización. Esta concepción parte del hecho de que la traducción es una operación dinámica, que no tiene un sentido estático y válido para todas las épocas y culturas. La traducción es la negación misma del concepto de universal que predominaba en las teorías de la traducción de los años sesenta. Al reescribir el original el traductor de literatura poscolonial puede optar por acentuar la diferencia. Se trata, pues, de un proceso inverso a la invisibilidad del traductor. Al traducir un texto excluido de los cánones literarios del sistema de recepción, o al usar estrategias marginales para traducir un texto, el traductor reivindica su presencia, hace oír su voz a través del eco de una cultura distinta a la de destino (como ocurre siempre en la recepción de literatura poscolonial). La adopción de esta estrategia es en parte una forma de resistencia contra el narcisismo cultural y el imperialismo que todavía prevalece en las culturas occidentales. La práctica visible de la traducción reconoce la discontinuidad irremediable que separa el texto de origen del texto traducido. Si bien las traducciones extranjerizadoras como las domesticadoras son parciales, en cuanto que son interpretaciones subjetivas del texto original, las primeras tienden a acentuar su parcialidad en lugar de matizarla.

De hecho, la distinción de Venuti entre una estrategia traductológica domesticadora y una tendencia extranjerizadora equivale a una orientación del texto final más cercana a la cultura de destino o a la de origen, respectivamente. A nuestro parecer, su postura claramente a favor de la primera con- 
tiene ciertos peligros para la traducción de literatura poscolonial: al traducir un texto poscolonial, que se basa en el principio de la diferencia, es muy fácil provocar una sensación de extrañamiento reproduciendo literalmente algunas estrategias narrativas del original en la lengua de destino. Porque no debemos olvidar que el objetivo último de un traductor de culturas no debe ser extranjerizar el texto porque sí, sino plasmarlo en la cultura de destino después de haber estudiado y entendido la cultura y el estilo propios del autor y el contexto en el cual va a integrarse la obra.

Para entender las consecuencias que puede acarrear una mala interpretación de la práctica visible de la traducción de literatura poscolonial, presentaremos algunos ejemplos de determinados problemas que planteó la traducción al catalán de A Varanda do Frangipani cuya resolución podía haber dado lugar a versiones radicalmente distintas de la que finalmente se publicó. Tres categorías de problemas traductológicos merecen una atención especial.

En primer lugar, el traductor debe adoptar un criterio coherente ante ciertos giros recurrentes en el portugués mozambiqueño, como son la ausencia de artículos, el superlativo por repetición - "O que queria lembrar, muitomuito, eram as mulheres que amei"33 (1996: 19), la inversión del orden sintáctico de los elementos de la frase - "Estava onde?"4 (1996: 49) - y el repetido uso de los prefijos des- e in- en palabras que, a pesar de proceder de la misma raíz latina, que permitiría a pesar de todo comprender el significado, no se reconocen en catalán bajo esa forma. El criterio general adoptado para resolver esta primera categoría de dificultades fue evitar entorpecer la lectura de la traducción mediante calcos que transmitirían una visión distorsionada de la naturaleza del original. Así, por ejemplo - usamos la cursiva para destacar lo que nos interesa - cuando Mia Couto escribe "Quando, enfim, tudo se acalmou, reinou um silêncio como se toda a terra tivesse perdido voz" (1996: 150), la versión en catalán incluye el artículo ausente: "Quan finalment tot va calmar-se, regnà un silenci com si tota la terra hagués perdut la veu"5 (1998: 150). En otro momento el narrador declara: "Xidimingo se inacreditava" (1996: 150) y "Pás e enchadas desrespeitavam o sagrado" (1996: 13), traducidos respectivamente mediante palabras que no reproducen los citados prefijos "Xidimingo no podia creure-s'ho" (1998: 150) y "Les pales i les aixades profanaven terra sagrada" (1998: 14).

En segundo lugar, el traductor no puede pasar por alto el universo tradicional que Mia Couto recrea en la novela y que se concreta en vocablos y expresiones en lenguas nacionales, en su mayoría explicados en el glosario al final del libro. Tal es el caso de la palabra muchém, 'termita' en la frase siguiente: "Meu corpo assentava sobre areia que haviam retirado de um morro de muchém" (1996: 17), que en la traducción se preservó tal cual aunque escrita en cursiva, como todos los términos incluidos en el glosario traducido. A pesar de la preciosa ayuda aportada por el glosario, la traducción al catalán amplió el elenco de expresiones, mitos y voces que requerían una explicación complementaria para el lector-receptor desconocedor del contexto africano del original. Palabras como cacimbo, 'niebla húmeda ca- 
racterística de ciertas regiones africanas' o expresiones como "O morcego chorou por causa da boca" (1996: 27), merecen pues una nota a pie de página.

Finalmente, coincidiendo con Michel Laban, cabe incluir en una tercera categoría las creaciones propias del autor, frecuentes en el caso de Mia Couto. Afortunadamente, al ser el portugués y el catalán lenguas emparentadas, y al utilizar el autor con frecuencia la formación de palabras por composición, la traducción pudo respetar en gran medida dichas creaciones. Sirvan los dos casos siguientes de ejemplo: "Sou desses mortos a quem não cortaram o cordão desumbilical” (1998: 12), en catalán "Sóc d'aquells morts a qui no van tallar el cordó desumbilical"10 (1998: 12) y "Cala, Xidimingo. Você é um arrota-peidos" Xidimingo. Ets un rotapets" (1998: 64).

$\mathrm{Si}$, contrariamente a los ejemplos que hemos observado, la estrategia adoptada para traducir los ejemplos de desviaciones respecto al portugués estándar que hemos descrito en primer lugar hubiera sido la plasmación palabra por palabra, el lector en catalán habría interpretado que estaba leyendo un texto procedente de una cultura por lo menos exótica. Las marcas de diferencia que hemos detectado no son más que ejemplos del portugués híbrido que se usa en Mozambique. La interferencia de las lenguas bantús con el portugués en este país africano ha dado lugar a una nueva variante lingüística que tiene sus propias normas independientemente de la evolución de la lengua en Portugal. La decisión de mantener construcciones extrañas, como la ausencia de artículos, el orden sintáctico alterado, la combinación aleatoria del tú y del usted, en la versión catalana, habría revelado que el traductor, al leer la versión original, no había considerado el portugués de Mozambique como una lengua autosuficiente, sino como una desviación de la norma portuguesa y su estrategia traductológica habría acentuado dicha impresión. El texto final así elaborado puede llevar al lector a adoptar una actitud falsamente indulgente cuando encuentra giros un poco extraños o abruptos en la lengua de llegada. La opción del traductor en este caso perjudica la imagen del Otro que viaja a través de esta obra. Por el contrario, si se considera la lengua del original como una lengua estándar, ¿qué necesidad hay de traducir literalmente el orden alterado de las palabras en la frase y de provocar un cierto extrañamiento en el lector de la traducción?

Los ejemplos que hemos presentado extraídos de la traducción de $A$ Varanda do Frangipani resaltan la importancia del papel del traductor en la transmisión de una determinada imagen del Otro y sacan a relucir en qué medida el hecho de adoptar una u otra estrategia repercute más allá del ámbito puramente literario, puesto que, por ejemplo, sugiere al lector poco informado la idea de que las ex-colonias no han sido capaces de aprender 'correctamente' las lenguas de los antiguos colonizadores. Queda, pues, demostrado que el traductor ante un texto poscolonial se ve en la obligación de tomar consciente o inconscientemente una postura sobre el estatus de la lengua de la cual traduce y de dar así respuesta a las siguientes cuestiones: ¿el inglés, el portugués, el francés usados por los escritores poscoloniales 
africanos tienen validez por sí mismos o bien son simples variantes exóticas del modelo europeo?, ¿la traducción debe reflejar la extrañeza que producen ciertos giros, expresiones y construcciones sintácticas en la lengua original?

\section{Hacia una ética de la traducción de culturas}

El traductor de culturas debe intentar parecerse al máximo al lector poscolonial definido por Samia Mehrez ${ }^{12}$ y en la medida de lo posible transmitir en su traducción la riqueza de matices del original, propósito que a veces requerirá una nota a pie de página o una explicación introductoria. Pero debe evitar que su traducción transmita un exotismo gratuito, fruto de la exaltación injustificada de la diferencia que supuestamente vehicula el original. Lo interesante de la teoría de la invisibilidad de Venuti es que nos recuerda que una buena traducción no es un texto definitivo, sino un intento de ajuste del texto de origen a una cultura de destino adaptado a unas circunstancias históricas, políticas y culturales concretas.

En definitiva, Venuti preconiza el relativismo, ensalza la subjetividad del traductor y propone centrar la atención en los textos originales. Hay una relación directa entre sus tesis y el discurso transgresor de la literatura poscolonial: la adopción de estrategias de extranjerización de los textos poscoloniales es lo que permitirá a la literatura y la teoría poscolonial realizar su propósito de agency, su función de agitadoras de las mentalidades occidentales para que superen los esquemas jerárquicos impuestos por décadas de dominación imperialista. Así lo explica Venuti: "The point is rather to elaborate the theoretical, critical and textual means by which translation can be studied and practiced as a locus of difference, instead of the homogeneity that widely characterizes it today" (1995: 42).

La práctica de la traducción de culturas en casos como el descrito por Michel Laban o como la novela de Mia Couto a la que nos hemos referido más arriba incluye con frecuencia el afrontar originales escritos en más de una lengua a la vez. El texto poscolonial oculto tras este mosaico lingüístico requiere una búsqueda del significado particular por parte del traductor, que implica la reconstrucción del universo híbrido desde el cual el escritor poscolonial toma la palabra. Tal como señala Graham, el texto multilingüe exige un tratamiento particular por parte de la teoría de la traducción. La búsqueda y restitución del significado ante tales creaciones literarias calidoscópicas, impelen al traductor a adoptar estrategias forzosamente adaptadas:

Une des limites des théories de la traduction: elles traitent trop souvent des passages d'une langue à l'autre et ne considèrent pas assez la possibilité pour des langues d'être impliquées à plus de deux dans un texte. Comment traduire un texte écrit en plusieurs langues à la fois? Comment 'rendre' l'effet de la pluralité? Et si l'on traduit par plusieurs langues à la fois, appellerat-on cela traduire? (1985: 215) 
En este artículo hemos podido analizar algunas de las respuestas que la teoría de la traducción y la teoría poscolonial ofrecen a estos interrogantes. Como hemos visto en el ejemplo de $A$ Varanda do Frangipani, los obstáculos particulares con los que se enfrenta un traductor de una obra poscolonial derivados del multilingüismo del texto de partida y del imaginario cultural híbrido en el que se inscribe, nos hacen tomar conciencia de un aspecto dominante que influirá de manera decisiva en el resultado de su labor: el peso de la imagen del Otro. El comparatista francés Daniel-Henri Pageaux, describe así la importancia del estudio de la imagen de la Otredad al abordar cualquier texto literario extranjero:

L'image 'littéraire' est envisagée comme un ensemble d'idées sur l'étranger prises dans un processus de littérarisation mais aussi de socialisation. Cette nouvelle perspective oblige le chercheur à tenir compte non seulement des textes littéraires, de leurs conditions de production et de diffusion, mais encore de tout matériau culturel avec lequel on a écrit, mais aussi pensé, mais encore vécu. Ce type de travail mène le chercheur à des carrefours problématiques où l'image tend à être un révélateur particulièrement éclairant des fonctionnements d'une idéologie (racisme, exotisme, par exemple, pour nous tenir à des questions concernant 'l'étranger tel qu'on le voit'). (1989: 135)

Si trasladamos estas palabras al ámbito de lo poscolonial y consideramos el marco de producción de este tipo de literatura, la imagen vehiculada en los textos del Otro poscolonial es la cara vista del imaginario social, lo que Maria Tymoczko describe como el metatexto cultural en el que se inspiran los escritores poscoloniales, que nunca es inocente. La dimensión extralinguiística de todo estudio sobre el Otro resaltada por Pageaux debe centrar la atención de todo aquel que aborde una traducción de culturas. Lo que nos importa aquí destacar es que la materia prima sobre la que opera un traductor poscolonial, las lenguas coloniales mestizadas, son el resultado de un largo proceso de imposición que de modo inesperado, entre los años 1960 y 1970 en el caso de las colonias africanas lusófonas, acabaron transformándose, en manos de las primeras generaciones de escritores poscoloniales, en instrumentos de liberación del yugo colonial. Los escritores poscoloniales que practican la traducción-creación recurren a la manipulación de las lenguas coloniales, conscientes de la carga política que supone moldear en provecho propio un capital cultural que les fue impuesto. El traductor de literatura poscolonial, lejos de interpretar las desviaciones en la estructura gramatical y en los distintos registros lingüísticos respecto a la lengua estándar, la introducción de términos importados de lenguas nacionales, las expresiones idiomáticas locales que salpican el texto original como algo anecdótico, por citar algunos de los rasgos del texto poscolonial africano que hemos destacado en este artículo, debe, por el contrario, tratar de comprender el contexto histórico, cultural y por consiguiente lingüístico en el que se ha creado el texto original. Porque lo que está en juego no es una simple transmisión de contenidos de una lengua a otra sino la apertura hacia unas culturas mestizas que hasta tiempos muy recientes vivían confinadas en el silencio. 


\section{Bibliografía}

\section{Literatura primaria}

Couto, Mia (1996). A Varanda do Frangipani. Lisboa: Caminho.

Couto, Mia (1998). El Balcó del Frangipani. (tr. G. López Heredia). Andorra la Vella: Límits.

\section{Literatura secundaria}

Adenjunmobi, Moradewun (1998). "Translation and Postcolonial Identity. African Writing and European Languages." The Translator. Special Issue: Translation \& Minority 4 (2), 163-181.

Bassnett, Susan (1993). Comparative Literature: A Critical Introduction. Oxford UK \& Cambridge USA: Blackwell.

Bassnett, Susan \& Harish Trivedi (eds) (1999). Post-colonial Translation, Theory and Practice. London \& New York: Routledge, 19-40.

Bhabha, Homi (1994). The Location of Culture. London: Routledge.

Brunel, Pierre \& Yves Chevrel (eds) (1989). Précis de Littérature Comparée. Paris: PUF, 133-177.

Carbonell, Ovidi (1997). Traducir al Otro: traducción, exotismo, poscolonialismo. Cuenca: Ediciones de la Universidad de Castilla-La Mancha.

Dingwaney, Anuradha \& Carol Mayer (eds) (1995). Between languages and cultures: translation and cross-cultural texts. Pittsburgh: University of Pittsburgh Press.

Graham, J. F. (ed.) (1985). Difference in Translation. Ithaca \& London: Cornell University Press.

Laban, Michel (1995). "La traduction des auteurs de langue portugaise dans le monde." Onzièmes Assises de la Traduction Littéraire. Arles: Actes Sud, 31-65.

Mehrez, Samia (1992). "Translation and the Post-colonial Experience: the Francophone North African Text.” L. Venuti (ed.) (1994). Rethinking Translation: Discourse, Subjectivity, Ideology. London \& New York: Routledge, 120-137.

Pageaux, Daniel-Henri (1989). "De l'imagerie culturelle à l'imaginaire." P. Brunel \& Y. Chevrel (eds) (1989). Précis de Littérature Comparée. Paris: PUF, 133-177.

Sengupta, Mahasweta (1995). "The Power of Images and Images of Power." A. Dingwaney \& C. Mayer (eds) (1995). Between Languages and Cultures: Translation and Cross-Cultural Texts. Pittsburgh: University of Pittsburgh Press.

Tymoczko, Maria (1999). "Post-colonial writing and literary translation." S. Bassnett \& H. Trivedi (eds) (1999). Post-colonial Translation, Theory and Practice. London \& New York: Routledge, 19-40.

Venuti, Lawrence (ed.) (1994). Rethinking Translation: Discourse, Subjectivity, Ideology. London \& New York: Routledge.

Venuti, Lawrence (1995). The Translator's Invisibility: a History of Translation. London \& NewYork: Routledge.

Venuti, Lawrence (1998). The Scandals of Translation: Towards an ethics of difference. London \& New York: Routledge. 
1 Para evitar cualquier confusión, quisiera aclarar que el proceso traductológico que aquí denomino traducción-creación, coincide con lo que Ovidi Carbonell describe como traducción cultural. Efectivamente, Carbonell explica este proceso como sigue: "La traducción cultural tiene lugar siempre que una experiencia ajena se interioriza y reescribe en la cultura en la que esa experiencia es recibida. Esa reescritura es esencial en cualquier caso de contacto cultural. Siempre hay un grado de intraducibilidad que permite la modificación del significado primitivo según las estructuras de representación de la cultura o lengua de destino. Esta adaptación es de hecho uno de los aspectos más importantes de la traducción cultural, puesto que puede allanar el camino hacia una modificación o incluso subversión del canon existente" (1997: 103).

2 Homi Bhabha, en su obra The Location of Culture utiliza el término de traducción cultural en un sentido esencialmente metafórico, para significar el proceso de situación de cada uno de los elementos o signos que componen una cultura poscolonial, al ser releídos o interpretados en un contexto que no es el suyo originario: "It becomes crucial to distinguish between the semblance and similitude of the symbols across diverse cultural experiences - literature, art, music ritual, life, death - and the social specificity of each of these productions of meaning as they circulate as signs within specific contextual locations and social systems of value. The transnational dimension of cultural transformation [...] makes the process of cultural translation a complex form of signification" (1994: 172). Los mecanismos sociales, las costumbres, los sistemas de valores que, según Bhabha, intervienen al descodificar signos de una cultura a otra, aunque no se refieran específicamente a la producción escrita, son elementos que hay que tener muy en cuenta a la hora de explicar la traducción de culturas tal como la entiendo en este artículo, como el viaje entre un texto poscolonial escrito en una lengua colonial y su traducción a otra lengua. Dicho de otro modo, el traductor de un texto poscolonial cuando trata de interpretar lo más correctamente posible lo que lee para restituirlo en otra lengua operando mínimas transformaciones debe afrontarse a un complejo entramado de desajustes, desconocimientos, prejuicios que separan las culturas occidentales de las culturas poscoloniales.

3 Literalmente: 'lo que quería recordar, mucho-mucho, eran las mujeres que amé'.

${ }^{4}$ Literalmente: ‘¿Estaba dónde?'.

5 'Cuando al fin todo se calmó, reinó un silencio como si toda la tierra hubiera perdido la voz'.

6 'Xidimingo no podía creerlo'.

7 'Las palas y las azadas profanaban tierra sagrada'.

8 'Mi cuerpo se asentaba sobre arena que habían retirado de un montículo de muchém'.

9 'El murciélago lloró por culpa de la boca', proverbio del Norte de Mozambique que alerta para que no se hable en exceso.

${ }_{10}$ 'Soy de esos muertos a quienes no cortaron el cordón desumbilical'.

11 'Calla, Xidimingo. Eres un eructa-pedos'.

${ }^{12}$ Sostiene Samia Mehrez en su artículo "Translation and the Post-colonial Experience: the Francophone North African Text", publicado en el volumen editado por Venuti, Rethinking Translation (véase bibliografía), que si existen escritores poscoloniales también podemos hablar de lectores poscoloniales, es decir, lectores capaces de entender la complejidad de matices semánticos y las connotaciones culturales del texto poscolonial porque forman parte de su misma cultura o porque dominan las distintas lenguas en las que está escrito el texto. Hay una diferencia fundamental entre estos lectores y los que leen el texto en su lengua original desde Europa, y que son totalmente o parcialmente ajenos a su contexto de creación. El lector poscolonial, pues, procedería del mismo contexto cultural que el escritor poscolonial, lo cual le confiere una base privilegiada para entender esta literatura. 